\title{
Tripterygium wilfordii Polyglycoside Ameliorated TNBS-Induced Colitis in Rats via Regulating Th I7/ Treg Balance in Intestinal Mucosa
}

This article was published in the following Dove Press journal: Journal of Inflammation Research

\author{
Cui Zhang' \\ Jingyi Ju' \\ Xiaohan Wu' \\ Jiaolan Yang $\mathbb{D}^{\prime}$ \\ Qinglu Yang' \\ Changqin Liu' \\ Liang Chen' \\ Xiaomin Sun ${ }^{1,2}$ \\ 'Gastroenterology Department, The \\ Shanghai Tenth People's Hospital, Tongji \\ University, Shanghai, People's Republic of \\ China; ${ }^{2}$ Gastroenterology Department, \\ The Shanghai Tenth People's Hospital, \\ Chongming Branch, Shanghai, People's \\ Republic of China
}

Purpose: To investigate the therapeutic effect of Tripterygium wilfordii polyglycoside (TWP), a derivative from a Chinese traditional herb, on 2,4,6-trinitrobenzenesulfonic acid (TNBS)-induced colitis, in a model for inflammatory bowel disease (IBD) in rats.

Methods: TWP was administrated to Wistar rats during TNBS-induced colitis to determine its therapeutic effect on active inflammation using the Quantitative Real-Time Polymerase Chain Reaction (qRT-PCR), flow cytometry, and Western blotting. Peripheral blood CD4 ${ }^{+}$ T-cells were isolated from patients with ulcerative colitis (UC) and incubated with TWP to verify its immune regulation mechanism by qRT-PCR and flow cytometry.

Results: Intragastric administration of TWP attenuated the severity of intestinal inflammation in TNBS-induced rat colitis, characterized by decreased DAI, histopathological scores, and expression of IL-6, TNF $\alpha$, IFN $\gamma$, and IL-17A in intestinal mucosa. Furthermore, TWP reduced IL-17 $\mathrm{A}^{+} \mathrm{CD} 4^{+}$T-cells, while enhanced Foxp3 ${ }^{+} \mathrm{CD} 25^{+} \mathrm{CD} 4^{+}$T-cells in peripheral blood, mesenteric lymph nodes (MLN), and spleen in rat colitis. Downstream signaling including ROR- $\gamma \mathrm{t}$, STAT3, and HIF1 $\alpha$ expression in intestinal mucosa were suppressed by TWP. In addition, incubation with TWP suppressed IL-17A ${ }^{+} \mathrm{CD} 4^{+}$T-cell differentiation, while it promoted Foxp $3^{+} \mathrm{CD} 25^{+} \mathrm{CD} 4^{+}$T-cell differentiation in $\mathrm{CD}^{+}{ }^{+}$T-cells isolated from UC patients.

Conclusion: TWP successfully ameliorated experimental rat colitis via regulating innate immune responses as well as Th17/Treg balance in intestinal mucosa, peripheral blood, MLN, and spleen. Moreover, the differentiation of peripheral blood $\mathrm{CD}^{+}{ }^{+}$-cell isolated from patients with UC was modulated by TWP. TWP may act as an optional complementary and alternative medicine for IBD.

Keywords: inflammatory bowel disease, Tripterygium wilfordii polyglycoside, intestinal mucosa immunity, T helper 17 cell, regulatory T-cell

\section{Introduction}

Inflammatory bowel disease (IBD), including Crohn's disease (CD) and ulcerative colitis (UC), is a chronic relapsing immune mediated disorder affecting the gastrointestinal tract. Increasing biological agents, eg, infliximab, vedolizumab, ustekinumab, and novel therapies, eg, fecal transplantation and leukapheresis, for IBD have kept emerging in recent decades. ${ }^{1-3}$ Since 5-aminosalicylic acid (5-ASA) has already achieved great success in inducing and maintaining remission in mild-tomoderate UC and mild CD, limited research concentrated on seeking novel drugs for mildly active IBD. However, there still exists numerous patients with IBD who
Correspondence: Xiaomin Sun

The Shanghai Tenth People's Hospital,

Tongji University, Yanchang Middle Road

No. 30I, Shanghai, People's Republic of

China

Tel +860216630 II 64

Emailsxmglcly@I63.com
Journal of Inflammation Research 2021:|4 1243-1255

1243 
are irresponsive or allergic to 5 -ASA. ${ }^{4,5}$ Switching the therapeutic drugs to azathioprine (AZA) or monoclonal antibodies (mAbs) is not always the best choice due to the adverse effects of immunosuppressants and the expensive cost of the biological agents, respectively. ${ }^{6}$

Tripterygium wilfordii polyglycoside (TWP, Leigongtengduogan Pian) is one of the functional natural products derived from Tripterygium wilfordii Hook. F. and is approved by National Medical Products Administration (NMPA) to be prescribed to patients with rheumatoid arthritis, nephrotic syndrome, ankylosing spondylitis, psoriasis, and systemic erythematosus lupus. ${ }^{7-10}$ The mechanisms of TWP suppressing immune responses are limited explored and remain elucidated. ${ }^{11,12}$ Tripterygium glycoside was proved to ameliorate experimental allergic encephalomyelitis (EAE) inflammation by inhibiting NF- $\mathrm{kB}$ p65 activation, simultaneously inducing $\mathrm{CD}^{+} \mathrm{T}$ cell apoptosis. ${ }^{13}$ Multi-glycoside of Tripterygium wilfordii Hook. F was capable of inhibiting IL-17A producing Th17 cells via interrupting phosphorylation of signal transducers and activators of transcription 3 (STAT3) and further potentially acted as a therapeutic choice for psoriasis. ${ }^{14}$ Moreover, Multi-glycoside of Tripterygium wilfordii Hook. F could alleviate diabetic nephropathy by suppressing p38 mitogen-activated protein kinase (MAPK) activation. ${ }^{15}$ Tripterygium glycoside fraction $\mathrm{n} 2$ can attenuate dextran sodium sulfate (DSS)-induced colitis via inducing T-cell apoptosis. ${ }^{16}$ There even existed a report that TWP was superior to 5-ASA in preventing the postoperative recurrence of $\mathrm{CD} .{ }^{17}$ Accordingly, whether TWP can induce intestinal inflammation remission in IBD is valuable to investigate.

In our study, TWP relieved 2,4,6-trinitrobenzenesulfonic acid (TNBS)-induced colitis in rats, characterized by decreased disease activity index (DAI), reduced proinflammatory cytokine expression, including tumor necrosis factor (TNF) $\alpha$, Interleukin (IL)-17A, IL-6, and Interferon (IFN) $\gamma$, and downregulated Th17, meanwhile it upregulated $\mathrm{T}$ regulatory cell (Treg) differentiation in peripheral blood, spleen, and mesenteric lymph nodes (MLN). Furthermore, the downstream signaling research suggested that orphan nuclear receptor $\gamma \mathrm{t}$ (ROR- $\gamma \mathrm{t}$ ), STAT3, hypoxiainducible factor $1 \alpha$ (HIF $1 \alpha$ ), and NF- $\mathrm{KB}$ p65 expression in intestinal mucosa were significantly suppressed by TWP administration. Additionally, ex vivo data indicated that TWP could directly inhibit Th17 while promoting Treg differentiation isolated from patients with active UC. The results provided us a beam of hope that TWP would function as an optional therapeutic medicine for IBD.

\section{Materials and Methods Subjects}

Patients diagnosed with active ulcerative colitis $(n=3)$ were enrolled in the Gastroenterology Department in Shanghai Tenth people's hospital of Tongji University. Five to $10 \mathrm{~mL}$ of peripheral vein blood was collected for further experiments. All participants signed informed consent prior to recruitment. All of the procedures and experiments were approved by the Human Ethics committee of Shanghai Tenth people's hospital (No.: SHSY-IEC-4.1/19-203/01), which was in accordance with the Declaration of Helsinki.

\section{Rats}

Wistar rats weighing from 180-200 g were purchased from Shanghai SLAC Laboratory animal Co., Ltd. Colitis was induced as previously described. ${ }^{18}$ Briefly, rats $(n=20)$ were divided into four groups: 50\% Ethanol, TNBS, TNBS+TWP, and TNBS+5-ASA. Firstly, $100 \mathrm{mg} / \mathrm{kg}$ TNBS (SigmaAldrich, St Louis, MO, USA) was dissolved in 50\% ethanol and intrarectally administrated at day 0 . Double distilled water, TWP, or 5-ASA was given intragastrically to the rats daily, respectively. Rats were sacrificed at day 14 and peripheral blood, MLN, spleen, and colonic mucosa were collected. The disease activity index (DAI) was assessed and recorded daily including diarrhea, bloody stool, and weight change (Supplementary Table 1). The colonic mucosa was analyzed by H\&E staining, and the histological score of each rat was assessed. The standards of histological score are shown in Supplementary Table 2. All of the experiments were performed three times repeatedly. All of the surgical procedures and experiments were approved by the Animal Ethics committee of Tongji University (No.: SYXKShanghai-2014-0026), which was in accordance with Laboratory animal Guidelines for ethical review of animal welfare (GB/T 35892-2018).

\section{Reagents}

TWP (Leigongtengduogan Pian, Z52020369, Han Fan pharmaceutical, Guizhou, China) was dissolved in Dimethyl sulfoxide (DMSO) for ex vivo experiments, while $25 \mathrm{mgTWP}$ was dissolved in $4 \mathrm{~mL}$ double distilled water for rat in vivo experiments. 


\section{Quantitative Real-Time Polymerase Chain Reaction (qRT-PCR)}

The total RNA was isolated with TRIzol reagent (Ambion, Thermo Fisher, Germany). The concentration and purity were measured with a NanoVue spectrophotometer (GE Healthcare, Germany). The cDNA was synthesized by PrimeScript $^{\mathrm{TM}}$ RT reagent Kit (Applied Biological Materials, Richmond, BC, Canada) and performed by ABI applied biosystem (Thermo Fisher). PCR conditions were as follows: $25^{\circ} \mathrm{C}$ for 10 minutes, $42^{\circ} \mathrm{C}$ for 15 minutes, and $85^{\circ}$ $\mathrm{C}$ for 5 minutes. qRT-PCR was performed according to SYBR green (TaKaRa, Dalian, China) instructions and determined by LightCycler ${ }^{\circledR} 96$ (Roche, Switzerland). RTPCR reaction conditions were as follows: $95^{\circ} \mathrm{C}$ for 5 seconds and $60^{\circ} \mathrm{C}$ for 34 seconds repeated for 40 cycles. All of the primers were synthesized by Shenggong (Shanghai, China) and $\beta$-actin served as a housekeeping gene. Primers for TNF $\alpha$, IL-17A, IL-6, and IFN $\gamma$ are listed in Supplementary $\underline{\text { Table } 3}$. The data were statistically analyzed by $2^{-\Delta \Delta \mathrm{Ct}}$.

\section{Immunohistochemistry Staining}

The intestinal mucosa was freshly collected from rats. The tissue was fixed with $10 \%$ paraformaldehyde for 24 hours, wrapped with paraffin, and sliced into $5 \mu \mathrm{m}$ thick sections. The sections were deparaffinated and rehydrated with dimethylbenzene and gradient ethanol, respectively. Antigen retrieval was performed with $\mathrm{pH}=6$ sodium citrate buffer. $3 \% \mathrm{H}_{2} \mathrm{O}_{2}$ was used to block endogenous peroxidase. Blocking nonspecific antibodies with $5 \%$ bovine serum albumin (BSA) for 30 minutes at $37^{\circ} \mathrm{C}$, the sections were incubated with mouse anti-rat primary antibodies, eg, IL-17A, IFN $\gamma$, TNFa, IL-6 (Abcam, Cambridge, UK), or control IgG at $4^{\circ} \mathrm{C}$ overnight. The sections were then incubated with HRP-conjugated anti-mouse IgG (Dako, Agilent, USA) at $37^{\circ} \mathrm{C}$ for 30 minutes. Finally, the sections were stained with diaminobenzidine (DAB) and haematoxylin and assessed with a microscope.

\section{Flow Cytometry}

The $1 \times 10^{6} / \mathrm{mL}$ isolated cells were suspended in the flow cytometry solution buffer (FACS buffer). Cell surface primary antibodies were stained at $4{ }^{\circ} \mathrm{C}$ for 30 minutes. The cells were fixed and punched with fixation and perforation mixed buffer (BD, eBioscience, San Diego, CA, USA) at $4^{\circ} \mathrm{C}$ for 30 minutes. Intracellular primary antibodies were stained at $4^{\circ} \mathrm{C}$ for 30 minutes. The cell subtypes were determined by BD LSR II. The statistics were analyzed by Flow Jo 10.0 (Tree Star, Ashland, OR, USA).

\section{Isolation of Cells from Peripheral Blood Mononuclear Cells (PBMCs), MLN, and Spleen in Rats}

PBMCs were extracted from rats retro-orbitally. Red blood cells were lysed with $10 \% \mathrm{NaCl}$ solution. MLN and spleen were collected and sliced into isolated cells with scissors and syringe. Single cells were suspended in FACS buffer after lysed with $10 \% \mathrm{NaCl}$ solution and filtered. Cell membrane and intracellular staining were performed as described above.

\section{Isolation of $\mathrm{CD}^{+}$T-Cells from Humans}

Peripheral blood cells were collected and isolated with Ficoll-Paque $^{\mathrm{TM}}$ (GE healthcare, Uppsala, Sweden) as described previously. ${ }^{19}$ Briefly, peripheral blood $(3 \mathrm{~mL})$ diluted with sterile PBS (3 $\mathrm{mL})$ was added to equal volume Ficoll. The tubes were vortexed for 30 minutes under $2,000 \mathrm{rpm}$ at $20^{\circ} \mathrm{C}$. PBMCs were collected and incubated with $\mathrm{CD} 4^{+}$microbeads for 30 minutes at $4^{\circ} \mathrm{C}$. $\mathrm{CD}^{+}$T-cell clones were expanded after being stimulated with plate-bound anti-CD3 $\mathrm{mAb}(5 \mathrm{mg} / \mathrm{mL})$, and antiCD28 mAb (2 mg/mL, eBioscience, San Diego, CA), followed by being stimulated with recombined human (rh) TGF $\beta$ (20 ng/mL), rh IL-6 (30 ng/mL), anti-IFN $\gamma$ $(20 \mu \mathrm{g} / \mathrm{mL})$, and anti-IL-4 $(20 \mu \mathrm{g} / \mathrm{mL})$ with PBS or TWP $(1.25 \mathrm{mg} / \mathrm{mL})$ for 72 hours. Differentiated $\mathrm{CD}^{+}$T-cells were collected for qRT-PCR. CD4 ${ }^{+}$T-cells were stimulated with mentioned cocktails for 5 days followed by being stimulated with PMA $(50 \mathrm{ng} / \mathrm{mL}$, Sigma-Aldrich, St Louis, MO, USA), ionomycin $(750 \mathrm{ng} / \mathrm{mL}$, SigmaAldrich), and Brefeldin A (3 $\mu \mathrm{g} / \mathrm{mL}$, eBioscience) for 5 hours. Differentiated $\mathrm{CD}^{+}{ }^{+}$T-cells were collected for cell membrane and intracellular staining, eg, CD25, IFN $\gamma$, IL17A, and FOXP3 for flow cytometer analysis.

\section{Western Blotting Analysis}

The whole intestinal tissue was lysed with PMSF and the whole protein levels were determined with BCA kit (Beyotime Biotechnology, Shanghai, China). Protein samples were separated with SDS-PAGE and transferred to a PVDF (Amresco, Sigma-Aldrich, St Louis, MO) membrane via electroblotting. The membranes were blocked with $10 \%$ non-fat milk for 1 hour at $4^{\circ} \mathrm{C}$. Subsequently, the 
A

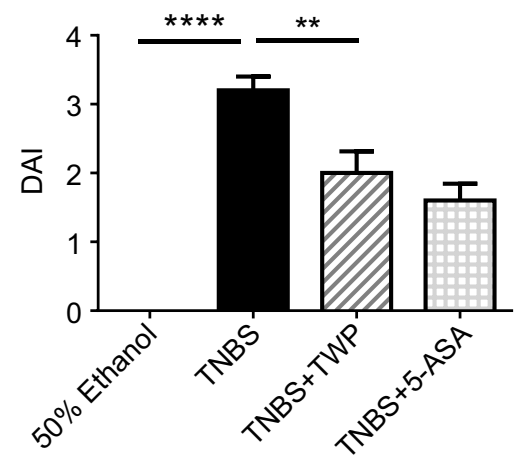

C

\section{$50 \%$ Ethanol TNBS}

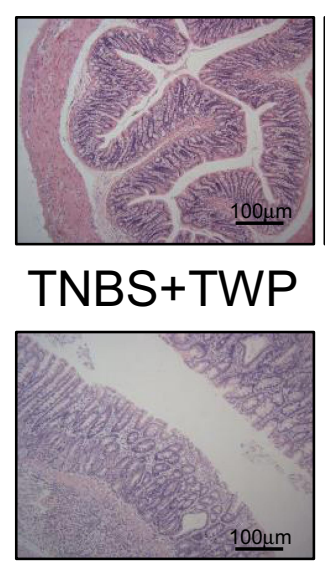

B

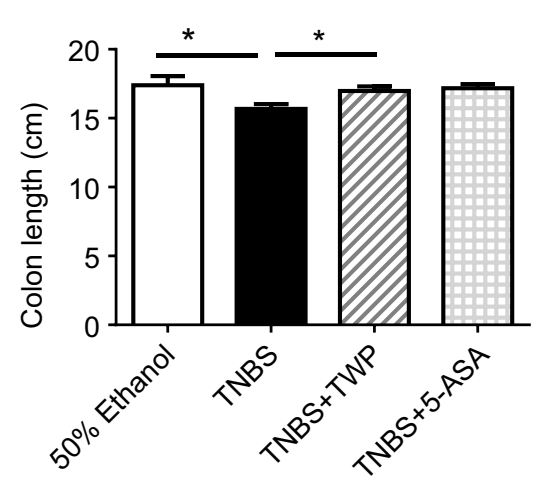

D
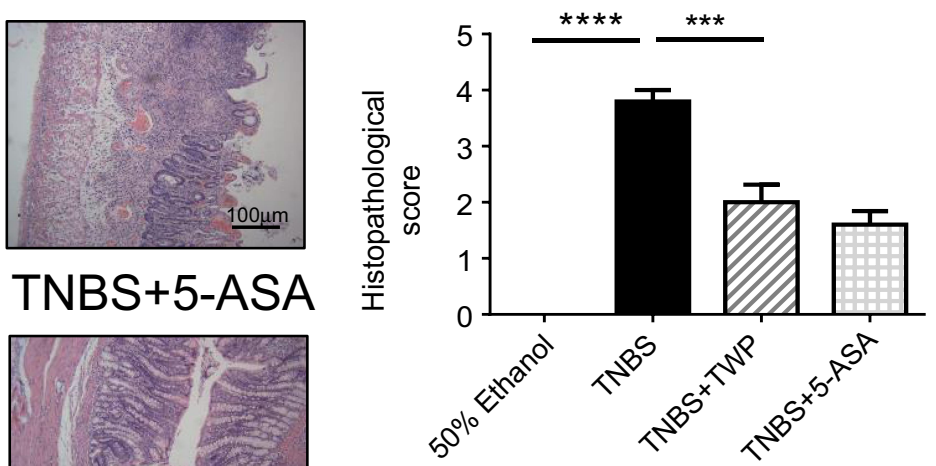

Figure I TWP ameliorates TNBS-induced colitis in rats. (A) Wistar rats ( $\mathrm{n}=5$ per group) were treated with $50 \%$ ethanol, TNBS ( $100 \mathrm{mg} / \mathrm{kg})$, TNBS + TWP $(50 \mathrm{mg} / \mathrm{kg})$, and TNBS+5-ASA (40 mg/kg), respectively, for 14 days. Disease activity index (DAl) including diarrhea, bloody stool, and weight loss were assessed on day I4. (B) Rats were sacrificed on day 14 and the length of colon was measured. (C) H\&E staining analysis of the colon mucosa was performed to compare the severity of the inflammation in each group. (D) The histopathological scores of the different groups. ${ }^{*} p<0.05,{ }^{* *} p<0.01,{ }^{* * *} p<0.00 \mathrm{I}, *_{* * *} p<0.000 \mathrm{I}$.

membranes were incubated with primary antibodies, eg, ROR- $\gamma \mathrm{t}$, STAT3, HIF $1 \alpha$, and NF-kB p65. Company and CAS ID of each antibody mentioned above are listed in Supplementary Table 4.

\section{Results}

\section{TWP Significantly Ameliorates}

\section{TNBS-Induced Colitis in Rats}

To investigate whether Tripterygium wilfordii polyglycoside (TWP) administration is protective in treating IBD, a TNBS-induced colitis model was applied. 3\% TNBS was given rectally to the rats while $50 \%$ ethanol served as control. Double distilled water (TNBS group), TWP (TWP group) and 5-ASA (5-ASA group) were intragastrically given to the rats daily for 2 weeks. Characteristics including weight loss, diarrhea, and bloody stool were graded and a disease activity index (DAI) were recorded. DAI of the TWP group was significantly reduced compared with the TNBS group, and comparable with the 5-ASA group (Figure 1A). The length of the colon from the TWP group and 5-ASA group were longer than that from the TNBS group (Figure 1B, and Supplementary Figure 1). The histopathological analysis revealed that TWP markedly relieved neutrophil and mononuclear cell infiltration and submucosa edema. The intestinal mucosal ulcers were deeply restored by TWP and 5-ASA (Figure 1C). The characteristics, including degree of mucosal inflammatory lymphocyte infiltration, crypt damage, the involved percentages of mucosal ulcer, and the thickness of the submucosa were assessed and scored. TWP and 5-ASA indeed alleviated rat colitis, illustrated by the decreased histological score (Figure 1D). The results 
show that neutrophils and mononuclear cells in intestinal mucosa were reduced by TWP. Whether TWP regulated the inflammatory mediators produced by those proinflammatory immune cells was worthwhile to investigate. Figure $2 \mathrm{~A}$ shows that the mRNA level of TNF $\alpha$ and IFN $\gamma$ in colonic mucosa was reduced by TWP. The protein level of IFN $\gamma$, IL-6, IL-17A, and TNF $\alpha$ in colonic mucosa was suppressed by TWP (Figure 2B, C and Supplementary Figure 2). These data indicate that pro-inflammatory cytokines were significantly downregulated by TWP.
A
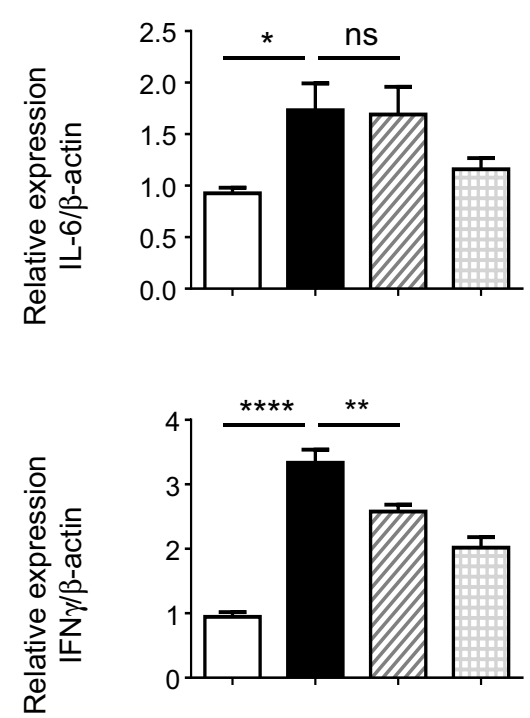

B

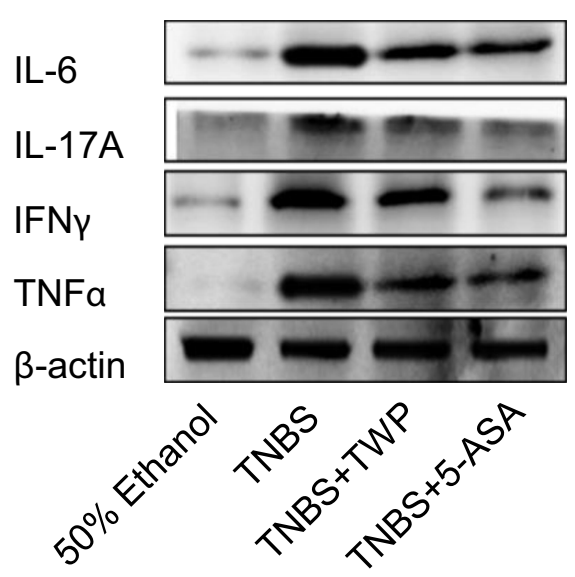

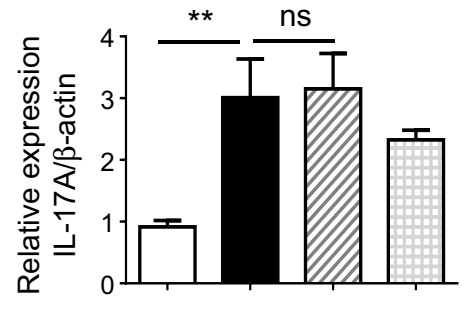
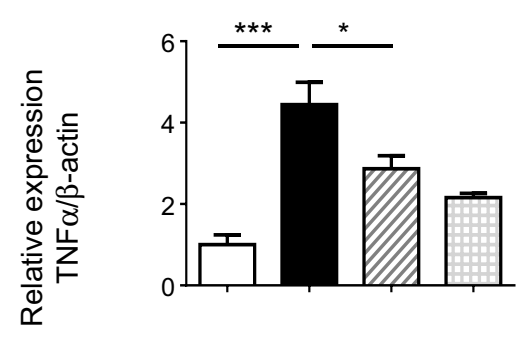

$50 \%$ Ethanol

TNBS

TNBS+TWP

TNBS+5-ASA

C
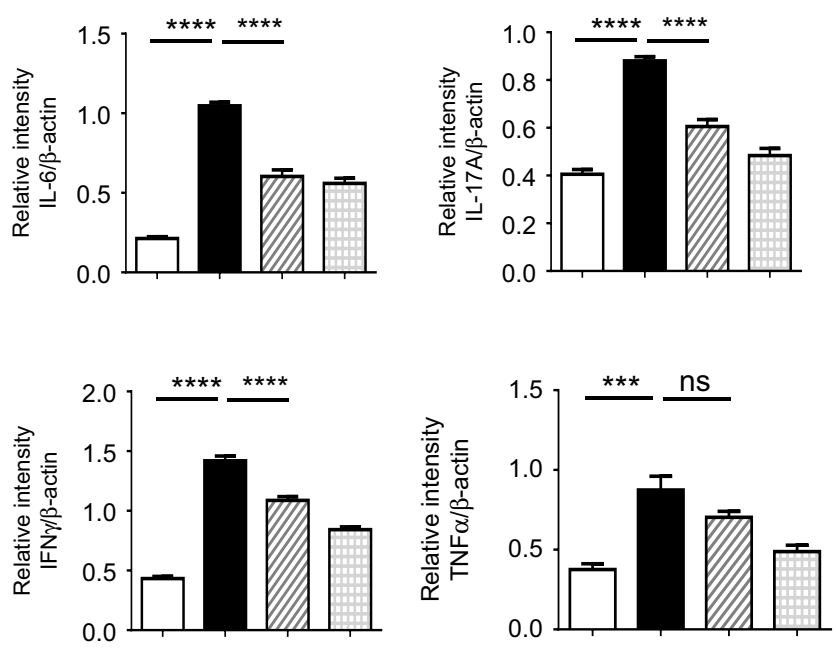

$50 \%$ Ethanol TNBS+TWP

TNBS

TNBS+5-ASA

Figure 2 TWP suppresses intestinal mucosal pro-inflammatory mediator production in rats. (A) Colon tissues were collected from the control group, TNBS group, TNBS +TWP group, and TNBS+5-ASA group. mRNA expression of IL-6, IL- I7A, IFN $\gamma$, and TNF $\alpha$ was measured by qRT-PCR. Statistically analysis was using $2^{-\Delta \Delta C t}$. (B and C) Western blotting analysis of protein level of IL-6, IL-I7A, IFN $\gamma$, and TNF $\alpha$ in colon. Gene and protein expression were normalized to $\beta$-actin. ${ }^{*} p<0.05$, ** $p<0.01$, ***p $<<0.00$ I. $* * * * 0<0.0001$.

Abbreviation: ns, no significance. 
Taken together, our data suggest that TWP as well as 5-ASA could alleviate TNBS-induced colitis in rats characterized by decreased DAI, longer colon length, fewer pro-inflammatory cell infiltrations, and down-regulated pathogenic cytokine expression in intestinal mucosa.

\section{TWP Regulates Th 17/Treg Balance in TNBS-Induced Colitis in Rats}

Since we had already found that Tripterygium wilfordii polyglycoside (TWP) could relieve colitis in rats probably via inhibiting pro-inflammatory mediator production, we sought to determine the cytokine producers. Given that IFN $\gamma$ producing Th1 cells and IL-17A-producing Th17 cells are important in the pathogenesis of $\mathrm{IBD},{ }^{20}$ the phenotypes of $\mathrm{CD}^{+} \mathrm{T}$-cells in rats were analyzed. Peripheral blood, spleen, and MLN cells were isolated from rats and immune cell types were detected by flow cytometer. The data indicated that the percentages of IL-17A ${ }^{+}$Th17 cells and IFN $\gamma^{+}$Th1 cells were decreased while Foxp $3^{+} \mathrm{CD} 25^{+}$Treg cells were elevated in $\mathrm{CD}^{+}$T-cells isolated from peripheral blood and spleen in rats treated with TWP. TWP slightly reduced the percentages of $\mathrm{IL}-17 \mathrm{~A}^{+} \mathrm{CD}^{+}$Th17 cells but did not impact on Foxp $3^{+} \mathrm{CD} 25^{+} \mathrm{CD} 4^{+}$Treg cells and $\mathrm{IFN} \gamma^{+} \mathrm{CD} 4^{+}$Th1 cells in MLN (Figures 3A-C and 4).

Collectively, these data suggested that TWP probably relieved the intestinal mucosal inflammation mainly via inhibiting Th17 differentiation while had limited influence on Th1 and Treg expansion in TNBS-induced rat colitis.

\section{Identification of Downstream Effectors of TWP in Inflamed Intestinal Mucosa}

Multiple transcription factors including STAT3, interferon regulatory factor 4 (IRF4), ROR- $\gamma$ t, and aryl hydrocarbon receptor (AHR) have been proved to be vital in maintaining the balance between Th17 and Treg cells. ${ }^{21}$ To investigate the downstream signaling effectors of TWP regulating Th17/Treg during colitis, we collected inflamed colonic mucosa from rats treated with or without TWP and determine the protein level of STAT3, HIF1 $\alpha$, NF- $\mathrm{kB}$ p 65 , and ROR- $\gamma$ t. As shown in Figure 5A and B, the expression of transcriptional factors mentioned above were decreased in inflamed intestinal mucosa from rats treated with TWP or 5-ASA, compared with that from rats treated with water.

Accordingly, the data provided us a hint that TWP probably down-regulated intestinal NF-кB p65, STAT3, HIF $1 \alpha$, and ROR- $\gamma \mathrm{t}$ to inhibit Th17 cell whilst promoting
Treg differentiation. Nevertheless, the direct target of the therapeutic drug is to be elucidated in the future.

\section{TWP Regulates Th I7/Treg Differentiation in Patients with UC}

To confirm the ability of TWP regulating Th17/Treg balance in IBD patients, ex vivo experiments were performed. Peripheral blood mononuclear cells were isolated from patients with active moderate UC, and stimulated with anti-CD3, anti-CD28, rh TGF $\beta$, rh IL-6, anti-IFN $\gamma$, and anti-IL-4 in the presence or absence with TWP. Proliferated and differentiated $\mathrm{CD} 4^{+} \mathrm{T}$-cells were collected and analyzed by flow cytometry. The results suggested that the percentages of $\mathrm{IL}-17 \mathrm{~A}^{+} \mathrm{CD} 4^{+} \mathrm{Th} 17$ cells were upregulated while that of $\mathrm{Foxp}^{+} \mathrm{CD}_{2} 5^{+} \mathrm{CD} 4^{+}$Treg cells were down-regulated by TWP (Figure 6A). Consistent with the differentiated cell subtypes, mRNA level of transcript factors including RORC and STAT3 expression were increased whereas Foxp3 expression was decreased by TWP (Figure 6B).

In summary, these data suggested that TWP simultaneously shaped the balance of Th17 and Treg in patients with UC via regulating RORC, STAT3, and Foxp3 expression.

\section{Discussion}

Multiple Chinese traditional medicine is proved to be effective for autoimmune disease, and the mechanisms of them in resolving inflammation flare remain elucidated. ${ }^{22-24}$ TWP was proved to be effective in relieving DSS-induced colitis by suppressing pro-inflammatory mediator production and modulating luminal microbiota. ${ }^{25-27}$ In our study, we found that TWP successfully reduced elevated amounts of proinflammatory cytokines, eg, IL-6, TNF $\alpha$, IFN $\gamma$, and IL-17A, prevented colon shortening, and relieved histologic inflammation in intestinal mucosa. Furthermore, Th17 cell differentiation was weakened, whereas Treg differentiation was enhanced in peripheral blood, MLN, and spleen from rats treated with TWP. TWP administration inhibited Th17 cell differentiation by suppressing RORC and STAT3 expression while promoting Treg cell differentiation by enhancing Foxp3 expression in $\mathrm{CD}^{+} \mathrm{T}$-cells isolated from peripheral blood of patients with active UC.

Multiple factors contribute to the pathogenesis of IBD, eg, susceptible genes, environmental triggers, luminal microbiota, and aberrant immune responses. ${ }^{28}$ Aggressive responses of intestinal $\mathrm{CD}^{+}$T-cells traditionally are 


\section{A $50 \%$ Ethanol TNBS TNBS+TWP TNBS+5-ASA}
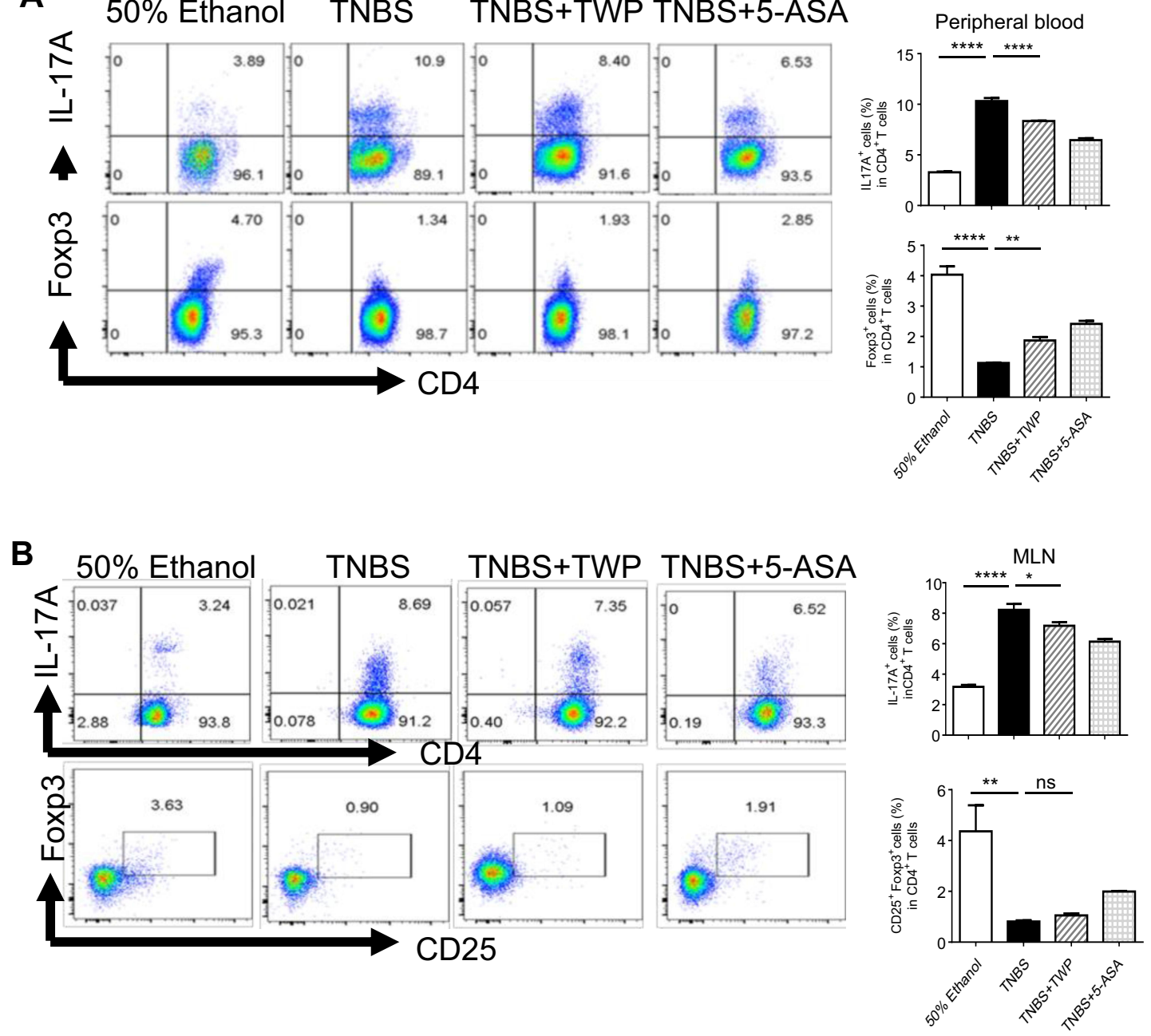

\section{C $50 \%$ Ethanol TNBS TNBS+TWP TNBS+5-ASA}
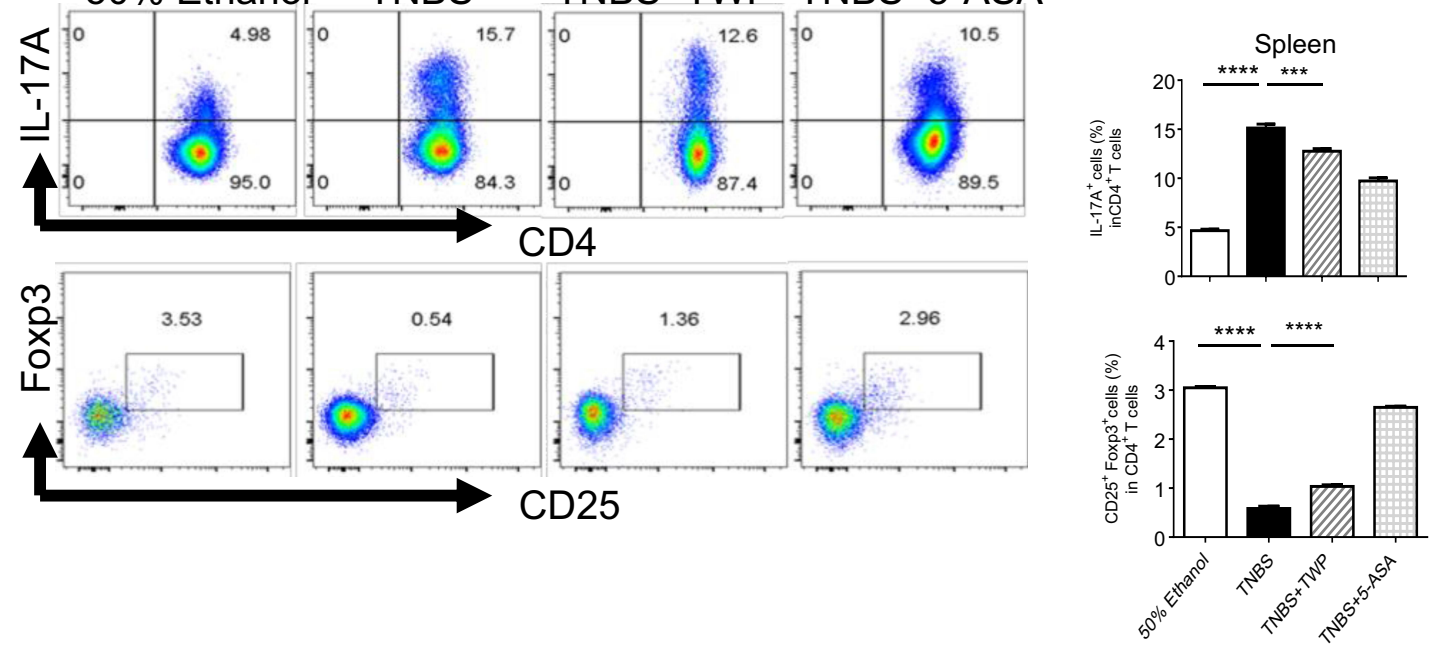

Figure 3 TWP suppresses ThI7 cell while promotes Treg differentiation in peripheral blood, MLN, and spleen from rats during colitis. Cells were isolated from peripheral

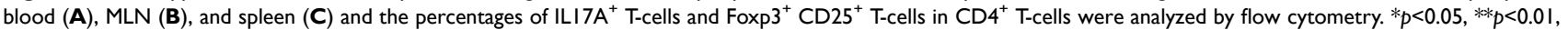
$* * * p<0.001$, ***** $p<0.0001$.

Abbreviations: ns, no significance; MLN, mesenteric lymph nodes. 


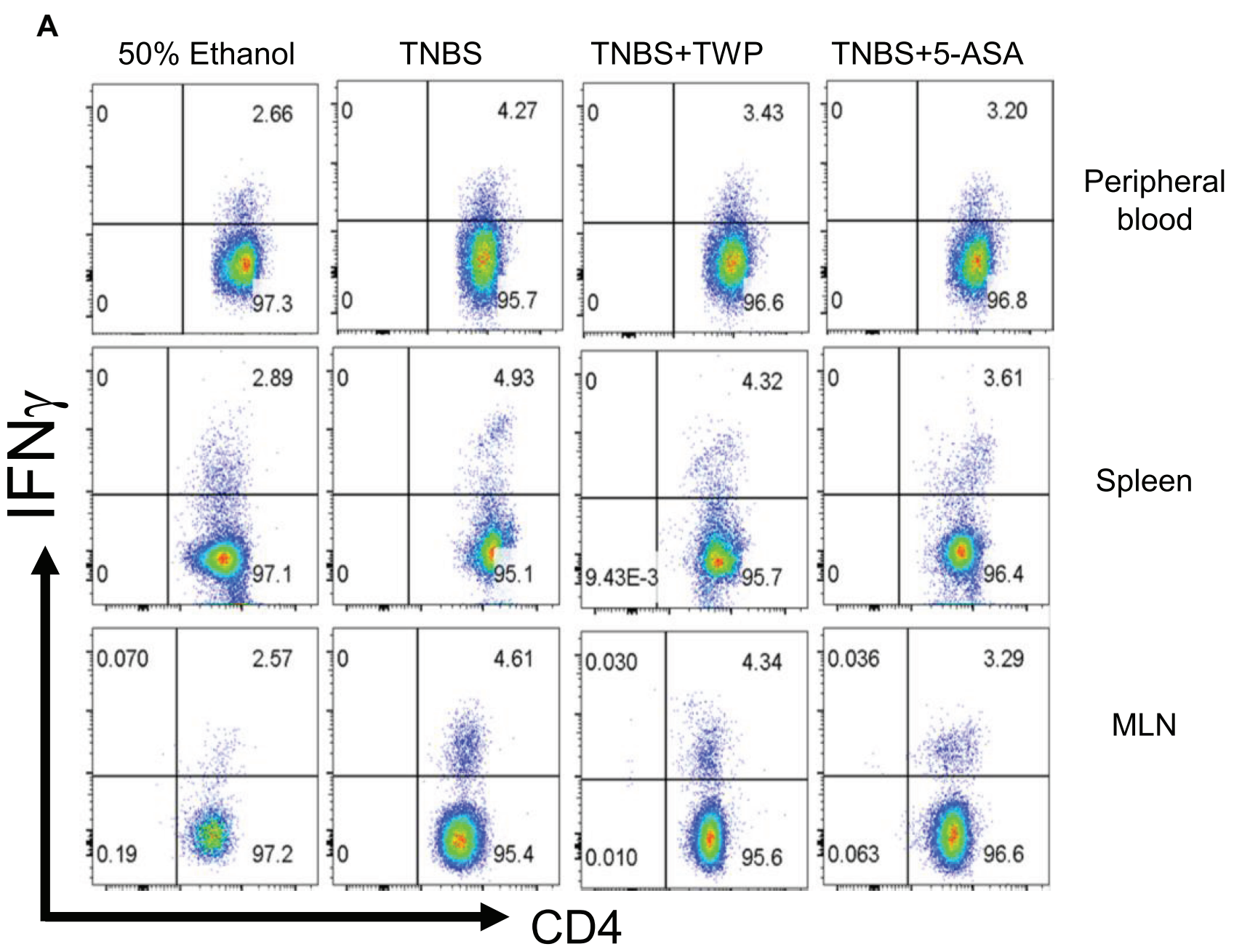

B
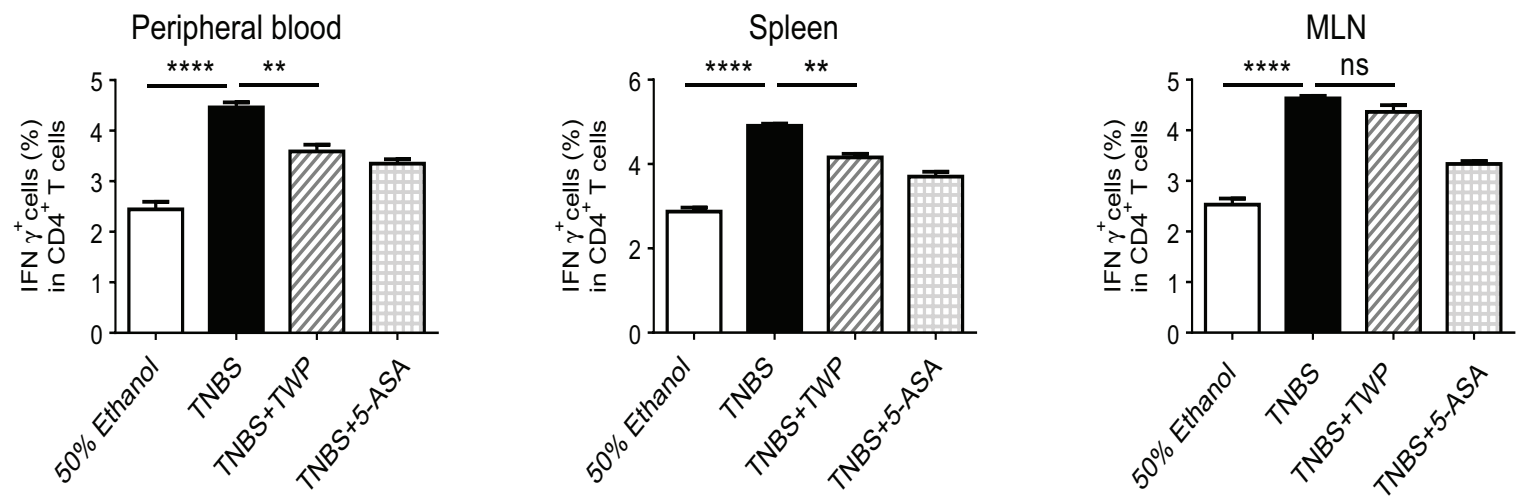

Figure 4 TWP suppresses ThI differentiation in peripheral blood and spleen, while does not impact on ThI differentiation in MLN. (A, B) Isolated cells from peripheral blood, MLN and spleen were collected and the percentages of IFN $\gamma^{+}$T-cells in $\mathrm{CD}^{+}$T-cells were analyzed by flow cytometry. ns, no significance. $* * p<0.0 \mathrm{I}$, $* * * * p<0.000 \mathrm{I}$.

considered to be vital in immune processes for that Th1 and Th2 cells were found to be raised in the intestinal lamina propria (LPL) from the patients with $\mathrm{CD}$ and $\mathrm{UC}$, respectively. ${ }^{20}$ Critically, Th17 cell and Treg cell balance is found to be similarly important in maintaining intestinal homeostasis and regulating inflammatory immune responses. ${ }^{20}$ Th17 cells are proved to protect the host from extracellular pathogens by releasing IL-17A, 
A

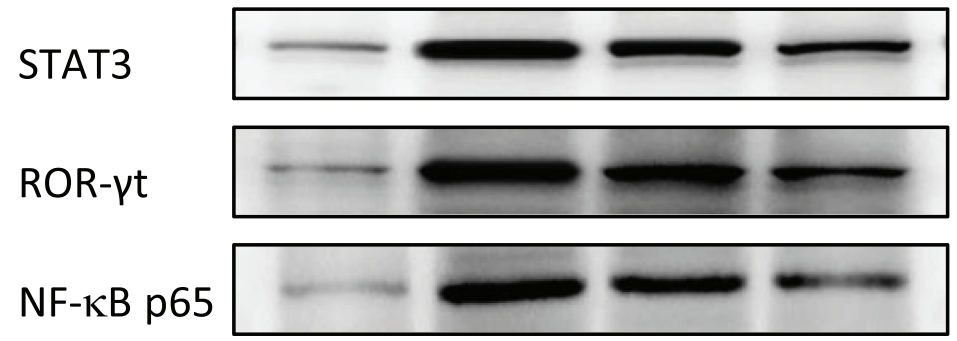

HIF1 $\alpha$

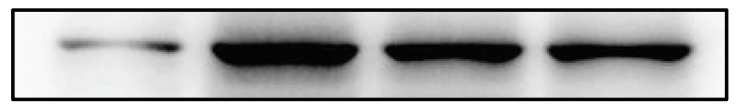

$\beta$-actin
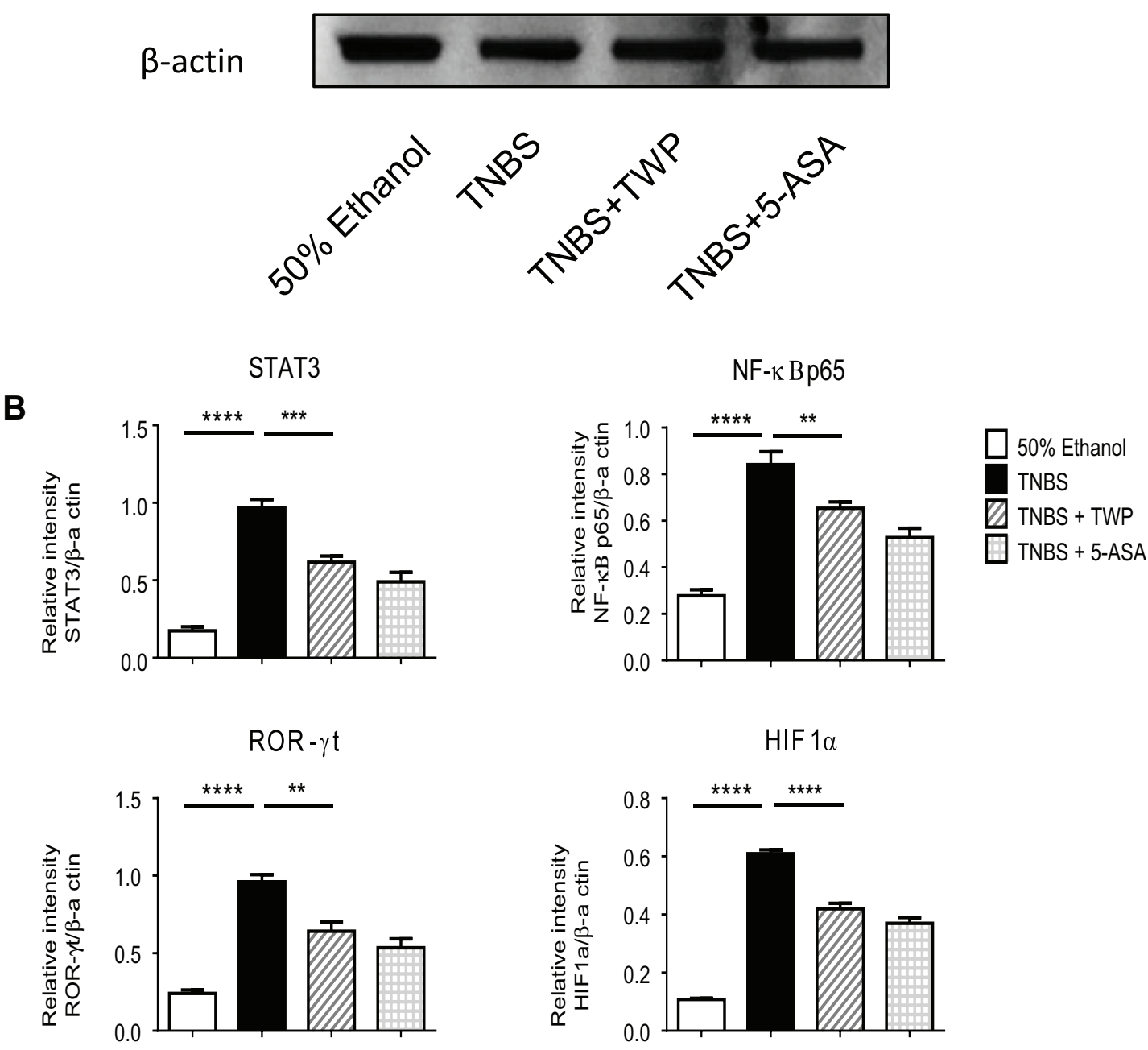

Figure 5 TWP inhibits transcriptional factors, eg, ROR- $\gamma$ t, NF- $\mathrm{kB}$ p65, HIFI $\alpha$, and STAT3 in colon. (A) Intestinal tissues were collected and the expression of ROR- $\gamma \mathrm{t}$, NF$\kappa B$ p65, HIFI $\alpha$, and STAT3 were determined by Western blotting. (B) The gray densities were measured and normalized to $\beta$-actin. $* * p<0.01, * * * p<0.00 \mathrm{I}, * * * * p<0.000 \mathrm{I}$.

IL-17F, IL-22, and IL-21 during intestinal homeostasis. In contrast, Th17 cells are detrimental in exaggerating inflame flare by secreting IL-17A and IL-17F during intestinal inflammation. ${ }^{29-31}$ In line with that triptolide could reduce splenic IL-17A-producing $\mathrm{CD}^{+}{ }^{+}$T-cells in an imiquimod-induced murine psoriasis model, we found that TWP showed a similar effect on $\mathrm{CD}^{+}$T-cells from spleen, MLN, and peripheral blood in the TNBS-induced rat colitis model. ${ }^{14}$ Nevertheless, TWP did not affect splenic Foxp $3^{+} \mathrm{CD} 25^{+} \mathrm{CD} 4^{+}$T-cells in a psoriasis murine model, while our study suggested that Treg cells were also enriched in spleens from the TWP group. ${ }^{14}$ The discrepancy might result from the different immune response process between psoriasis and IBD. Consistent with the 
A
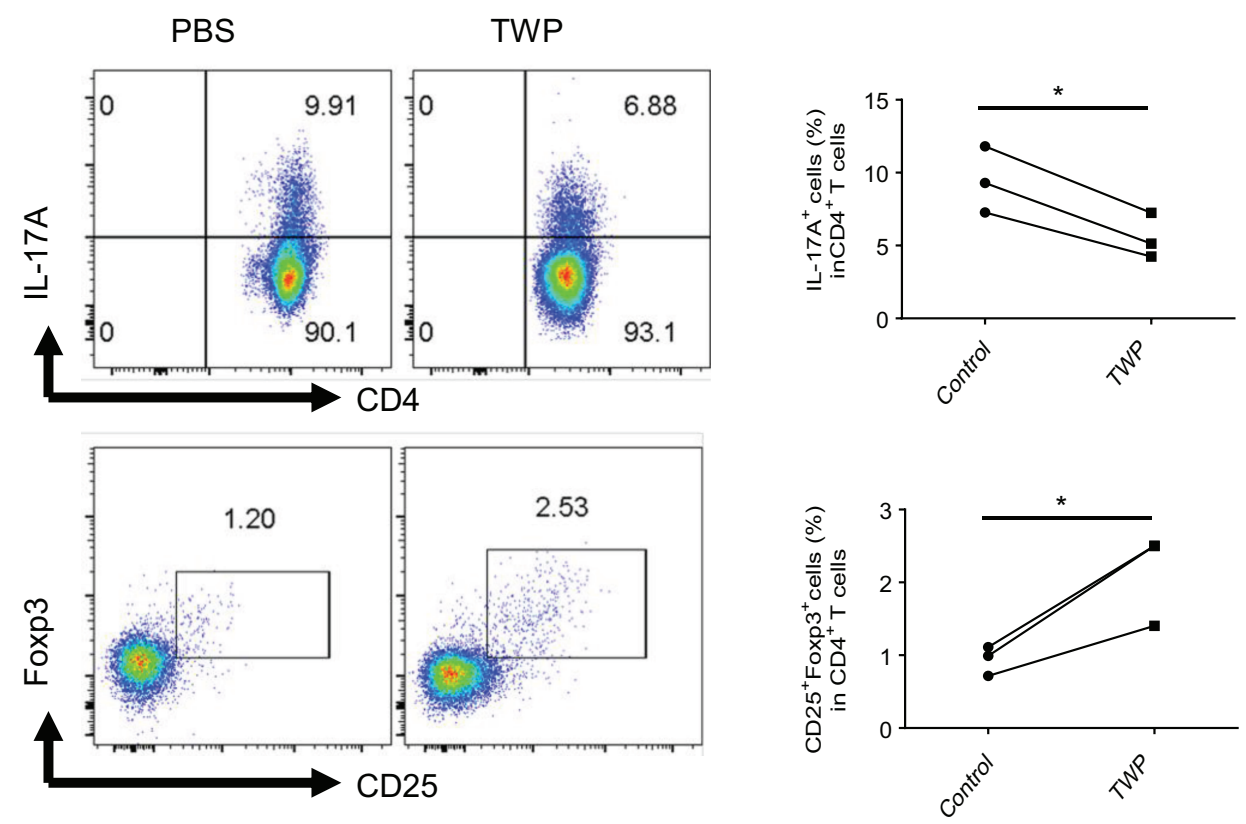

B
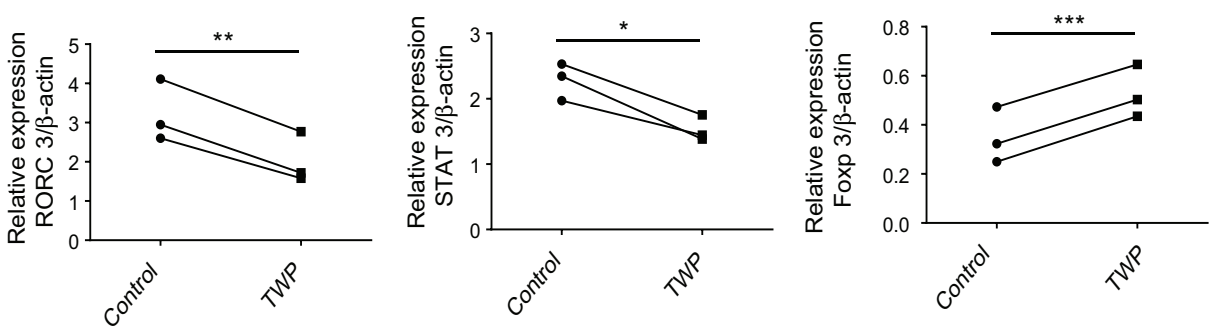

Figure 6 TWP reduces IL-17A-producing CD4 $4^{+}$T-cells while augments Foxp $3^{+} \mathrm{CD} 25^{+} \mathrm{CD} 4^{+}$T-cells in peripheral blood from patients with active UC. (A) Peripheral blood $\mathrm{CD}^{+}$T-cells were isolated from patients with active $\mathrm{UC}(\mathrm{n}=3)$ and stimulated with anti-CD3 $(5 \mathrm{mg} / \mathrm{mL})$, anti-CD28 $(2 \mathrm{mg} / \mathrm{mL})$, rh TGF $\beta(20 \mathrm{ng} / \mathrm{mL})$, rh IL-6 (30 ng/mL), antiIFN $\gamma(20 \mu \mathrm{g} / \mathrm{mL})$, and anti-lL-4 $(20 \mu \mathrm{g} / \mathrm{mL})$ in the absence or presence of TWP $(1.25 \mathrm{mg} / \mathrm{mL})$ for 5 days. The percentages of IL-17A ${ }^{+} \mathrm{T}_{\text {-cells }}$ and Foxp $3^{+}$CD25 $5^{+} \mathrm{T}$-cells in $\mathrm{CD}^{+}$T-cells were analyzed by flow cytometer. (B) Peripheral blood CD4 ${ }^{+}$T-cells isolated from patients with UC $(\mathrm{n}=3)$ were stimulated with anti-CD3 $(5 \mathrm{mg} / \mathrm{mL})$, antiCD28 $(2 \mathrm{mg} / \mathrm{mL})$, rh TGFB $(20 \mathrm{ng} / \mathrm{mL})$, rh IL-6 $(30 \mathrm{ng} / \mathrm{mL})$, anti-IFN $\gamma(20 \mu \mathrm{g} / \mathrm{mL})$, and anti-IL-4 $(20 \mu \mathrm{g} / \mathrm{mL})$ with or without TWP $(1.25 \mathrm{mg} / \mathrm{mL})$ for $72 \mathrm{hours}$. Expression of RORC, STAT3, and Foxp3 was determined by qRT-PCR. $* p<0.05, * * p<0.01$, ***p $<0.001$.

augmented Th17 cell pool in the intestinal mucosa in the TWP group, our data also indicated that the protein level of IL-17A was increased whereas the mRNA level of that was comparable between the TWP group and TNBS group. The results suggested that TWP suppressed IL$17 \mathrm{~A}$ probably via reducing protein production other than regulating mRNA level. TWP might interrupt the IL-17A mRNA translation or promote degradation of IL-17A protein. Further research about the direct target of TWP is worthwhile to investigate.

Subsequently, we sought to screen the potential downstream signaling factors that regulate Th17/Treg balance. Th17 cells differentiation from naïve $\mathrm{CD} 4^{+} \mathrm{T}$-cells can be divided into three transcriptional phases including induction (early phase), onset of phenotype and amplification (intermediate phase), and stabilization of IL-23 signaling (late phase), each of which is controlled by different regulatory networks. ${ }^{21}$ TGF $\beta$ induces naïve $\mathrm{CD}^{+}$T-cells to differentiate into Th17 cells and Treg cells. The presence of IL-6, IL-1 $1 \beta$, and IL-23 inhibits Treg, whereas drives Th17 differentiation ex vivo. ${ }^{32}$ IL-6/IL-6R/JAK2/STAT3 signaling pathway activation is involved in the early phase of Th17 differentiation. ${ }^{33,34}$ Our data indicated that IL- 6 expression was increased in intestinal mucosa from TNBS-induced colitis in rats, and TWP diminished both mRNA and protein expression of IL-6 though less significantly than 5-ASA. Accordingly, STAT3 expression in intestine from rats and PBMCs derived from patients was also suppressed by TWP. These results suggested that TWP might 
suppress Th17 differentiation via inhibiting IL-6 mediated the IL-6R/JAK2/STAT3 signaling pathway in $\mathrm{CD}^{+}$T-cells. We did not explore the IL-6 producers for previous reports have found triptolide has inhibited polarization of IL-6-producing M1 macrophages in intestinal mucosa during DSS-induced colitis. ${ }^{25}$ We presumed that TWP might modify macrophage polarization in TNBS-induced colitis as well. Further investigation needs to be performed to confirm this hypothesis. ROR- $\gamma \mathrm{t}$ triggers Th17 cells to transit to the intermediate phase. ${ }^{21}$ Inhibition of IL-17A worsens the severity of disease in Crohn's disease but blockade of ROR- $\gamma \mathrm{t}$ activation can restore Citrobacter rodentium-induced colitis by inhibiting Th17 cell differentiation. ${ }^{35-37}$ Thus, we investigated whether ROR- $\gamma \mathrm{t}$ expression was modulated by TWP. Correspondently, TWP indeed suppressed ROR- $\gamma \mathrm{t}$ expression in the intestine from rats as well as RORC in PBMCs derived from patients. These results provided evidence that TWP impacted on the intermediate phase of Th17 differentiation. Moreover, HIF1o acts as a metabolic sensor which can react to the hypoxia, can bind to Foxp3 in naïve $\mathrm{CD} 4^{+}$T-cells, which further attenuate Treg development. ${ }^{38}$ In accordance with the report, our date indicated that TWP reduced HIF1 $\alpha$ expression in the intestine. Collectively, these data suggested that TWP might influence the intestinal Th17/Treg balance via regulating a series of transcriptional factors including STAT3, ROR- $\gamma \mathrm{t}$, and HIF1 $\alpha$. However, the critical transcriptional factors that TWP directly targeted is underlying explored.

Pathogenic IFN $\gamma$ production is related to Th1 expansion in inflamed mucosa from IBD. ${ }^{39}$ Repressing IFN $\gamma$ and IL-4 is crucial for Th17 cell transit to the late phase. ${ }^{21}$ Therefore, it cannot be ignored to seek the function of TWP on IFN $\gamma$-producing Th1 differentiation during colitis. Our data showed that TWP generated lower levels of IFN $\gamma$ responses in intestine and reduced the percentages of Th1 cells in peripheral blood and spleen. However, no difference of the Th1 cells was observed between the TNBS group and TWP group in draining MLN. Considering that macrophages can secrete IFN $\gamma$ during inflammation and triptolide can modify macrophage polarization, ${ }^{25,40}$ we speculated that TWP might modulate macrophages rather than Th1 cell function in intestinal mucosa during colitis. Natural killer cells and innate lymphoid cells can generate IFN $\gamma,{ }^{40}$ hence we cannot rule out that TWP functions on those innate immune cells during colitis. Since we have planned to mainly focus on the mechanisms of TWP modulating $\mathrm{CD}^{+}$T-cells, how TWP regulates other innate immune cells is limitedly investigated in this study.
As mentioned above, the existence of aberrant innate immune response has crucial implications for the pathogenesis of IBD. Aggressive production of proinflammatory cytokines including IL-1 $\beta$, IL-6, IL-8, and TNF $\alpha$ contributes to the mucosal inflame set-off and expansion simultaneously. ${ }^{41}$ Given that inhibition of TNF $\alpha$ with infliximab exhibits effective therapeutic function on patients with IBD, we sought to figure out whether TWP regulated intestinal TNF $\alpha$. Our data indicated that TWP constrained both mRNA and protein level of TNF $\alpha$ in intestinal mucosa during colitis, probably via interrupting intracellular NF- $\mathrm{NB}$ signaling pathway activation.

Accumulative evidences have proved that Tripterygium wilfordii Hook. F. and its derivates can alleviate colitis via shaping macrophage polarization, reducing pro-inflammatory mediators, inducing T-cell apoptosis, and modulating gut microbiota composition. ${ }^{16,25-27}$ Our study provided evidence that TWP could also modulate Th17 as well as Treg differentiation via regulating innate immune responses as well as transcriptional factors that controlled the balance between Th17 and Treg. Particularly, our study found that TWP could directly polarize $\mathrm{CD} 4^{+}$T-cells derived from patients with IBD, and the mechanism research revealed an important roles of transcription factors in the differentiation process, which was consistent with the results from rats.

\section{Conclusion}

TWP mainly regulated intestinal innate immune response via reducing TNF $\alpha$ and IL-6 production, which further influenced adaptive immunity via shaping Th17 and Treg differentiation balance, attributing to resolution of TNBSinduced colitis in rats. STAT3, HIF1 $\alpha$, and ROR- $\gamma \mathrm{t}$ mediated pathogenic Th17 cell differentiation was suppressed while protective Treg cell differentiation was promoted by TWP. Ex vivo experiment data from isolated cells from patients with active UC demonstrated that TWP also directly suppressed Th17 while promoting Treg differentiation via modifying transcriptional factors, eg, RORC, STAT3, and FOXP3. These data suggested that TWP might act as an optional complementary and alternative medicine for patients with mild-to-moderate $\mathrm{UC}$ and mild $\mathrm{CD}$, especially for those who are irresponsive or allergic to 5-ASA.

\section{Acknowledgments}

This work was financially supported by grants from the Science and Technology Commission of Shanghai Municipality (16ZR1426600) and the National Natural Science Foundation of China (81900491). We 
acknowledge Dr. Zhanju Liu from Gastroenterology department, Shanghai Tenth People's Hospital, Tongji University, Shanghai, China for his contributions to the experiment design and manuscript revision.

\section{Disclosure}

The authors declare no competing financial interests and conflicts of interest in this work.

\section{References}

1. Neurath MF. Current and emerging therapeutic targets for IBD. Nat Rev Gastroenterol Hepatol. 2017;14:269-278. doi:10.1038/ nrgastro.2016.208

2. Kim DH, Cheon JH. Pathogenesis of inflammatory bowel disease and recent advances in biologic therapies. Immune Netw. 2017;17:25-40. doi:10.4110/in.2017.17.1.25

3. Schreiner P, Neurath MF, Ng SC, et al. Mechanism-based treatment strategies for IBD: cytokines, cell adhesion molecules, JAK inhibitors, gut flora, and more. Inflamm Intest Dis. 2019;4:79-96. doi: $10.1159 / 000500721$

4. Sehgal P, Colombel JF, Aboubakr A, et al. Systematic review: safety of mesalazine in ulcerative colitis. Aliment Pharmacol Ther. 2018;47:1597-1609. doi:10.1111/apt.14688

5. Heap GA, So K, Weedon M, et al. Clinical features and HLA association of 5-aminosalicylate (5-ASA)-induced nephrotoxicity in inflammatory bowel disease. J Crohns Colitis. 2016;10:149-158. doi:10.1093/ecco-jcc/jjv219

6. Shah JA, Cathryn M, Edwards CSP. Should azathioprine and 5 -aminosalicylates be coprescribed in inflammatory bowel disease an audit of adverse events and outcome. Eur $J$ Gastroenterol Hepatol. 2008;20:169-173. doi:10.1097/MEG.0b013e3282f16d50

7. Hou W, Liu B, Xu H. Triptolide: medicinal chemistry, chemical biology and clinical progress. Eur J Med Chem. 2019;176:378-392. doi:10.1016/j.ejmech.2019.05.032

8. Luo D, Zuo Z, Zhao $\mathrm{H}$, et al. Immunoregulatory effects of Tripterygium wilfordii Hook $\mathrm{F}$ and its extracts in clinical practice. Front Med. 2019;13:556-563. doi:10.1007/s11684-018-0649-5

9. Zhou YY, Xia X, Peng WK, et al. The effectiveness and safety of Tripterygium wilfordii Hook. $\mathrm{F}$ extracts in rheumatoid arthritis: a systematic review and meta-analysis. Front Pharmacol. 2018;9:356. doi:10.3389/fphar.2018.00356

10. Han R, Rostami-Yazdi M, Gerdes S, et al. Triptolide in the treatment of psoriasis and other immune-mediated inflammatory diseases. $\mathrm{Br}$ $J$ Clin Pharmacol. 2012;74:424-436. doi:10.1111/j.1365-2125.2 012.04221.X

11. Jiang X, Cao G, Gao G, et al. Triptolide decreases tumor-associated macrophages infiltration and M2 polarization to remodel colon cancer immune microenvironment via inhibiting tumor-derived CXCL12. J Cell Physiol. 2020.

12. Li XJ, Jiang ZZ, Zhang LY. Triptolide: progress on research in pharmacodynamics and toxicology. $J$ Ethnopharmacol. 2014;155:67-79. doi:10.1016/j.jep.2014.06.006

13. Qiu J, You X, Wu G. Effects of Tripterygium glycoside treatment on experimental autoimmune encephalomyelitis. Mol Med Rep. 2017;16:8283-8288. doi:10.3892/mmr.2017.7627

14. Zhao J, Di T, Wang Y, et al. Multi-glycoside of Tripterygium wilfordii Hook. f. ameliorates imiquimod-induced skin lesions through a STAT3-dependent mechanism involving the inhibition of Th17-mediated inflammatory responses. Int $J$ Mol Med. 2016;38:747-757. doi:10.3892/ijmm.2016.2670
15. Wu W, Yang JJ, Yang HM, et al. Multi-glycoside of Tripterygium wilfordii Hook. f. attenuates glomerulosclerosis in a rat model of diabetic nephropathy by exerting anti-microinflammatory effects without affecting hyperglycemia. Int J Mol Med. 2017;40:721-730. doi:10.3892/ijmm.2017.3068

16. Yang YQ, Wu YF, Xu FF, et al. Tripterygium glycoside fraction n2: alleviation of DSS-induced colitis by modulating immune homeostasis in mice. Phytomedicine. 2019;58:152855. doi:10.1016/j. phymed.2019.152855

17. Ren J, Wu X, Liao N, et al. Prevention of postoperative recurrence of Crohn's disease: Tripterygium wilfordii polyglycoside versus mesalazine. J Int Med Res. 2013;41:176-187. doi:10.1177/03000605 12474744

18. He C, Shi Y, Wu R, et al. miR-301a promotes intestinal mucosal inflammation through induction of IL-17A and TNF-alpha in IBD. Gut. 2016;65:1938-1950. doi:10.1136/gutjnl-2015-309389

19. Ma C, Wu W, Lin R, et al. Critical role of CD6highCD4+ T cells in driving Th1/Th17 cell immune responses and mucosal inflammation in IBD. J Crohns Colitis. 2019;13:510-524. doi:10.1093/ecco-jcc/jjy179

20. Geremia A, Biancheri P, Allan P, et al. Innate and adaptive immunity in inflammatory bowel disease. Autoimmun Rev. 2014;13:3-10. doi:10.1016/j.autrev.2013.06.004

21. Yosef N, Shalek AK, Gaublomme JT, et al. Dynamic regulatory network controlling TH17 cell differentiation. Nature. 2013;496:461-468. doi:10.1038/nature11981

22. Salaga M, Zatorski H, Sobczak M, et al. Chinese herbal medicines in the treatment of IBD and colorectal cancer: a review. Curr Treat Options Oncol. 2014;15:405-420. doi:10.1007/ s11864-014-0288-2

23. Guo BJ, Bian ZX, Qiu HC, et al. Biological and clinical implications of herbal medicine and natural products for the treatment of inflammatory bowel disease. Ann N Y Acad Sci. 2017;1401:37-48. doi:10.1111/nyas. 13414

24. Lin SC, Cheifetz AS. The use of complementary and alternative medicine in patients with inflammatory bowel disease. Gastroenterol Hepatol (N Y). 2018;14:415-425.

25. Tang B, Zhu J, Zhang B, et al. Therapeutic potential of triptolide as an anti-inflammatory agent in dextran sulfate sodium-induced murine experimental colitis. Front Immunol. 2020;11:592084. doi:10.3389/ fimmu.2020.592084

26. Wu H, Rao Q, Ma GC, et al. Effect of Triptolide on dextran sodium sulfate-induced ulcerative colitis and gut microbiota in mice. Front Pharmacol. 2019;10:1652. doi:10.3389/fphar.2019.01652

27. Li Y, Yu C, Zhu WM, et al. Triptolide ameliorates IL-10-deficient mice colitis by mechanisms involving suppression of IL-6/STAT3 signaling pathway and down-regulation of IL-17. Mol Immunol. 2010;47:2467-2474. doi:10.1016/j.molimm.2010.06.007

28. Xavier RJ, Podolsky DK. Unravelling the pathogenesis of inflammatory bowel disease. Nature. 2007;448:427-434. doi:10.1038/ nature 06005

29. Wu W, Chen F, Liu Z, et al. Microbiota-specific Th17 Cells: Yin and Yang in regulation of inflammatory bowel disease. Inflamm Bowel Dis. 2016;22:1473-1482. doi:10.1097/MIB.0000000000000775

30. Bacher P, Hohnstein T, Beerbaum E, et al. Human anti-fungal Th17 immunity and pathology rely on cross-reactivity against Candida albicans. Cell. 2019;176:1340-1355 e15. doi:10.1016/j.cell.2019.01.041

31. Galvez J. Role of Th17 cells in the pathogenesis of human IBD. ISRN Inflamm. 2014;2014:928461. doi:10.1155/2014/928461

32. Gaublomme JT, Yosef N, Lee Y, et al. Single-cell genomics unveils critical regulators of Th17 cell pathogenicity. Cell. 2015;163:1400-1412. doi:10.1016/j.cell.2015.11.009

33. Mitsuyama K, Matsumoto S, Masuda J, et al. Therapeutic strategies for targeting the IL-6/STAT3 cytokine signaling pathway in inflammatory bowel disease. Anticancer Res. 2007;27:3749-3756. 
34. Mihara M, Hashizume M, Yoshida H, et al. IL-6/IL-6 receptor system and its role in physiological and pathological conditions. Clin Sci (Lond). 2012;122:143-159. doi:10.1042/CS20110340

35. Withers DR, Hepworth MR, Wang X, et al. Transient inhibition of ROR- $\gamma$ t therapeutically limits intestinal inflammation by reducing TH17 cells and preserving group 3 innate lymphoid cells. Nat Med. 2016;22:319-323. doi:10.1038/nm.4046

36. Hueber W, Sands BE, Lewitzky S, et al. Secukinumab, a human anti-IL-17A monoclonal antibody, for moderate to severe Crohn's disease: unexpected results of a randomised, double-blind placebo-controlled trial. Gut. 2012;61:1693-1700. doi:10.1136/ gutjnl-2011-301668

37. Ogawa A, Andoh A, Araki Y, et al. Neutralization of interleukin-17 aggravates dextran sulfate sodium-induced colitis in mice. Clinical Immunol. 2004;110:55-62. doi:10.1016/j.clim.2003.09.013
38. Dang EV, Barbi J, Yang HY, et al. Control of T(H)17/T(reg) balance by hypoxia-inducible factor 1. Cell. 2011;146:772-784. doi:10.1016/ j.cell.2011.07.033

39. $\mathrm{Wu} \mathrm{W}, \mathrm{He} \mathrm{C}$, Liu C, et al. miR-10a inhibits dendritic cell activation and Th1/Th17 cell immune responses in IBD. Gut. 2015;64:1755-1764. doi:10.1136/gutjnl-2014-307980

40. Mezouar S, Mege JL. Changing the paradigm of IFN-gamma at the interface between innate and adaptive immunity: macrophage-derived IFN-gamma. J Leukoc Biol. 2020;108:419-426. doi:10.1002/ JLB.4MIR0420-619RR

41. Neurath MF. Cytokines in inflammatory bowel disease. Nat Rev Immunol. 2014;14:329-342. doi:10.1038/nri3661

\section{Publish your work in this journal}

The Journal of Inflammation Research is an international, peerreviewed open-access journal that welcomes laboratory and clinical findings on the molecular basis, cell biology and pharmacology of inflammation including original research, reviews, symposium reports, hypothesis formation and commentaries on: acute/chronic inflammation; mediators of inflammation; cellular processes; molecular mechanisms; pharmacology and novel anti-inflammatory drugs; clinical conditions involving inflammation. The manuscript management system is completely online and includes a very quick and fair peerreview system. Visit http://www.dovepress.com/testimonials.php to read real quotes from published authors.

Submit your manuscript here: https://www.dovepress.com/journal-of-inflammation-research-journal 